\title{
Role of Brainstem Evoked Response Audiometry in Evaluating Sensorineural Hearing Loss in Diabetic Patients
}

https://doi.org/10.47210/bjohns.2021.v29i2.481

Deepika Goswami, ${ }^{1}$ Saurabh Srivastava, ${ }^{1}$ Anuja Bhargava, ${ }^{1}$ S M Faiz, ${ }^{1}$ Zeba Siddiqi, ${ }^{2}$ Sneha Gupta, ${ }^{1}$ Varun Kacker ${ }^{1}$

$\underline{\text { Introduction }}$

\section{ABSTRACT}

Diabetes has become a global epidemic. Hearing loss has been long associated with diabetes. Brainstem Evoked Response Audiometry (BERA) is an objective, non-invasive, electro diagnostic test that not only evaluates the functional integrity of the subcortical auditory pathway but also provides topo-diagnosis of hearing loss. This study aims to identify the role BERA in detecting hearing loss early in diabetic patients.

Materials and Methods

In this study a total of 210 patients were taken and subjected to blood glucose levels followed by PTA were divided into two groups. Group I $(n=105)$ consisted of diabetic patients with sensorineural hearing loss $(S N H L)$ and Group II ( $n=105)$ had age and sex matched non-diabetics with SNHL. All the patients were evaluated with BERA.

$\underline{\text { Results }}$

All the patients were subjected to Brain Stem Evoked Response Audiometry (BERA). Absolute latency of Wave I, III, V, I-III, III-V and I-V were assessed for both the ears. In both ear Absolute latency were significantly higher in diabetics as compared to non-diabetic patients

\section{Conclusion}

The findings of present study showed that the severity of hearing loss was significantly higher in diabetic patients as compared to non-diabetic controls. Level of glycemic control showed a possible link with severity of hearing loss.

$\underline{\text { Keywords }}$

Audiometry, Evoked Response; Hearing Loss, Sensorineural; Diabetes Mellitus

$\mathrm{D}$ iabetes can be defined as a condition characterized by higher serum glucose, which can be a result of defects in insulin secretion, insulin action, or both. ${ }^{1,2}$ Diabetes has become a global epidemic affecting children, adolescents, and adults and can be traced to a group of heterogeneous disorders with

1 - Department of Otorhinolaryngology, Era's Lucknow Medical College, Era's University, Sarfarazganj, Hardoi Road, Lucknow

2 - Department of Internal Medicine, Era's Lucknow Medical College, Era's University, Sarfarazganj, Hardoi Road, Lucknow

\section{Corresponding author:}

Dr Anuja Bhargava

email: anujabhargava@rediffmail.com the common elements of hyperglycaemia and glucose intolerance. $^{3}$ Diabetes is growing at an exponential rate all around the world and soon is to be an epidemic in many countries including India. ${ }^{4}$ According to predictions the global prevalence of diabetes is to double globally from 171 million in 2000 to 366 million in 2030 with a maximum increase in India. ${ }^{5}$ Though obesity is considered a major risk factor in diabetes and India has lower obese and overweight rates, the prevalence of diabetes in India is confounding when compared to western and European countries. ${ }^{6}$ Diabetes is a metabolic disorder which eventually causes hyperglycemia. Generally, the injurious effects of hyperglycemia are separated into macrovascular complications (coronary artery disease, peripheral arterial disease, and stroke) and microvascular complications (diabetic nephropathy, 
neuropathy, and retinopathy). ${ }^{7}$ Hearing loss has been long associated with diabetes but conflicting results have been reported by many contemporary studies, where some studies suggested that sensorineural hearing loss (SNHL) may be caused due to diabetes, ${ }^{8,9,10}$ whereas others have failed to find any association. ${ }^{11,12,13}$ Cochlear microcirculation provides the cochlea with energy and substrates, carries away metabolic wastes, and helps maintain cochlear homeostasis. The functions of the inner ear depend on the stability of its internal environment supported by microcirculation. While it is clear that compromised cochlear blood supply can lead to cochlear dysfunction, ${ }^{14,15,16}$ details of injury mechanisms in diabetic hearing loss such as regulation of cellular transduction signals and neural, humoral and autonomous regulation of microcirculation are subject to debate and yet to be thoroughly studied.

Brainstem Evoked Response audiometry (BERA) is a simple procedure to detect early changes in cochlear nerve and CNS pathway. BERA, which is an objective, non-invasive, electro diagnostic test that not only evaluates the functional integrity of the subcortical auditory pathway but also provides topo diagnosis of hearing loss. ${ }^{17}$ The technique records the Brainstem Auditory Evoked Potentials (BAEP) from the ear and vertex in response to brief auditory stimulation, which are then assessed through the auditory pathway upto the midbrain. ${ }^{18}$ Waves which are depicted by BERA represents the neuronal activity which occurs at different sites of brainstem. Wave-I: distal portion auditory nerve relative to brainstem, Wave-II: proximal portion of the auditory nerve relative to the brain stem, Wave-III: cochlear nucleus, Wave-IV : superior olivatory complex, Wave-V: lateral lemniscus, Wave-VI: inferior colliculus and, Wave-VII: medial geniculate body. While these five wave forms are the basic observed waveforms, the inter-peak latencies I-III, III- V, and I-V and amplitude ratio of $\mathrm{V} / \mathrm{I}$ waves can be calculated further.

BERA differentiates between the cochlear and retrocochlear pathology. It helps to know the exact site of lesion along the auditory pathway and also the hearing threshold. This study aims to identify the role BERA in detecting hearing loss early in type 2 diabetic patients.

\section{Materials and Methods}

This cross-sectional cohort study had been conducted for a period of 24 months with the patients presenting with complaint of hearing loss in the OPD of Department of Otorhinolaryngology and Internal Medicine. Patients were categorized into two groups as under:

Group I (Diabetic Group): Old and newly diagnosed patients of type II Diabetes mellitus as per ADA diagnostic criteria (A random blood sugar equal to or greater than $200 \mathrm{mg} / \mathrm{dl}$ OR fasting blood sugar equals to or greater than $126 \mathrm{mg} / \mathrm{dl} \mathrm{OR}$ with a $\mathrm{HbA} 1 \mathrm{c}$ of $6.5 \%$ or higher) 19,20 in the age group of 30-65 years, with sensorineural hearing loss were included in Group I.

Group II (Non-Diabetic : Control Group): Subjects with sensorineural hearing loss who are non diabetics and they were matched for age and sex with the study group (Group I).

Patients who gave history of Hearing loss due to exposure to loud noise or intake of ototoxic drugs (e.g. Aminoglycosides, Diuretics, Quinine), history of stroke (CVA)/Hypertension or known neurological disorder, history of any middle ear and external ear pathology, known patients of Type 1 Diabetes mellitus or gestational diabetes mellitus, iatrogenic Diabetes mellitus due to steroids, hydrochlorthiazide, patients with end stage liver/kidney or cardiac disease or those who refused to give consent were excluded from the study.

All the patients with complaints of hearing loss and conforming to the sampling frame were invited to participate in the study. All the patients were subjected to thorough clinical examination including complete ENT examination and were subjected to normal routine investigation including blood glucose (fasting glucose, random sugar, $\mathrm{HbAlc}$ ). Hearing loss of all the patients were assessed by Pure Tone audiometry (PTA) and BERA. All the BERA parameters and blood glucose levels were compared. Demographic details, clinical findings including that of ENT examination, laboratory and BERA parameters were recorded on a separate case record form for all the cases. Data collected was recorded on computer which was used for analysis. The statistical analysis was done using SPSS (Statistical 


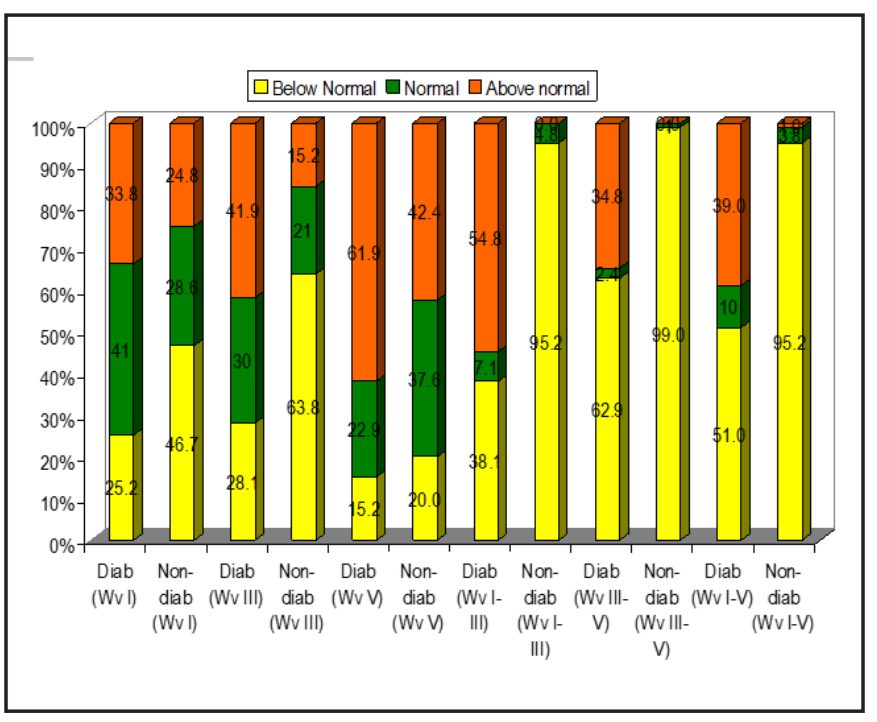

Fig.1. Comparison of Sensori Neural Hearing Loss amongst Diabetic and Non-Diabetic Patients

Package for Social Sciences) Version 15.0 statistical Analysis Software.

\section{Results}

A total of 210 patients with complaints of hearing loss and conforming to the sampling frame were enrolled in the study. Blood glucose levels (Fasting, Random and HbAlc) levels were estimated. Based on glycaemic levels, patients were divided into two groups as under. Out of 210 patients enrolled in the study, $105(50.0 \%)$ were diagnosed cases of diabetes and rest $105(50.0 \%)$ patients were non-diabetic. Age of patients enrolled in the study ranged between 30 and 58 years, mean age was $40.89 \pm 5.77$ years. Difference in age of diabetic and nondiabetic patients enrolled in the study was not found to be significant ( $41.19 \pm 5.86$ vs. $40.59 \pm 5.69$ years). Mean Random and Fasting blood sugar levels of diabetic patients were $163.77 \pm 49.12 \mathrm{mg} / \mathrm{dl}$ and $130.70 \pm 23.86$ $\mathrm{mg} / \mathrm{dl}$. HbA1c level was $6.42 \pm 1.33$ (range: $5-14$ ).

Patients enrolled in the study were suffering from diabetes from 2 to 18 years (mean $6.23 \pm 2.68$ years. Moderately severe hearing loss was documented with PTA in higher proportion of diabetic ears as compared to non-diabetic ears $(6.7 \%$ vs. $0.0 \%)$ while lower degree of hearing loss (Mild and Moderate) was observed in higher proportion of non-diabetic ears as compared to diabetic ears. This association was found to be significant statistically. All the patients were subjected to Brain Stem Evoked Response Audiometry (BERA). Absolute latency of Wave I, III, V, I-III, III-V and I-V were assessed for both the ears. Absolute latency of all the wave forms mentioned above were significantly higher in ears of diabetic as compared to non-diabetic patients. Normal range of Wave I is $1.55-1.75 \mathrm{~ms}$, Wave III is $3.8 \mathrm{~ms}$, Wave V is $5.5-5.85 \mathrm{~ms}$, of Wave I-III 2 ms, Wave I-V 4 ms, Wave III-V 2 ms. Absolute latency

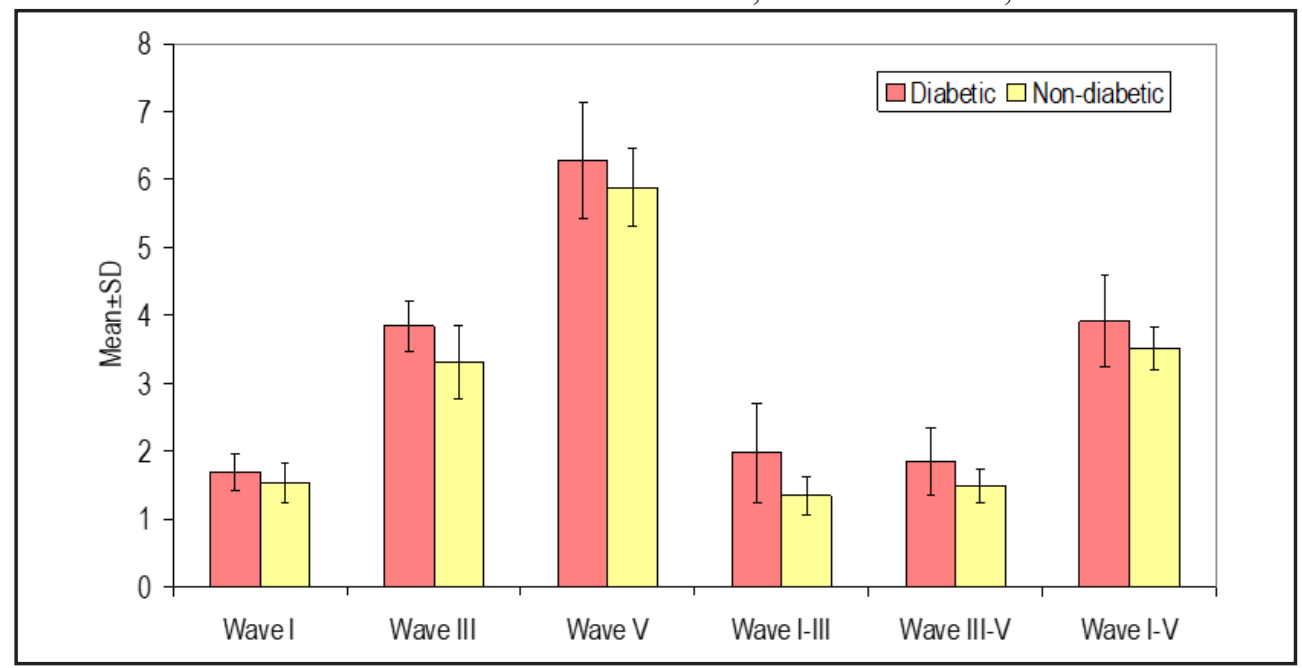

Fig. 2. Comparison of absolute latency of waves (BERA) amongst diabetic and non-diabetic Patients 
Table I: Correlation of HbA1c levels with BERA and Pure Tone Audiometry parameters (diabetic patients only)

\begin{tabular}{|c|c|c|c|c|}
\hline & \multicolumn{2}{|c|}{ PEARSON'S CORRELATION } & \multicolumn{2}{c|}{ STATISTICAL SIGNIFICANCE } \\
\cline { 2 - 5 } & $\begin{array}{c}\text { COEFFICIENT } \\
(\mathbf{R})\end{array}$ & $\begin{array}{c}\text { DIRECTION/ } \\
\text { STRENGTH OF } \\
\text { CORRELATION }\end{array}$ & 'P' & $\begin{array}{c}\text { LEVEL OF } \\
\text { SIGNIFICANCE }\end{array}$ \\
\hline Wave I & $\mathbf{0 . 0 5 8}$ & Positive; Weak & $\mathbf{0 . 4 0 1}$ & Not Significant (NS) \\
\hline Wave III & $\mathbf{0 . 0 3 2}$ & Positive; Weak & $\mathbf{0 . 6 5 5}$ & NS \\
\hline Wave V & $\mathbf{0 . 2 7 5}$ & Positive; Weak & $<\mathbf{0 . 0 0 1}$ & Highly significant \\
\hline Wave I-III & $\mathbf{- 0 . 0 0 6}$ & Inverse; Weak & $\mathbf{0 . 9 3 2}$ & NS \\
\hline Wave III-V & $\mathbf{- 0 . 0 5 1}$ & Inverse; Weak & $\mathbf{0 . 4 5 8}$ & NS \\
\hline Wave I-V & $\mathbf{- 0 . 0 6 1}$ & Inverse; Weak & $\mathbf{0 . 3 8 3}$ & NS \\
\hline Air Cond. & $\mathbf{0 . 0 1 1}$ & Positive; Weak & $\mathbf{0 . 8 7 6}$ & NS \\
\hline Bone Cond. & $\mathbf{0 . 0 3 3}$ & Positive; Weak & $\mathbf{0 . 6 3 3}$ & NS \\
\hline
\end{tabular}

of Waves was classified as below normal, Normal and above normal of standard values. (Fig.1) Significant differences in absolute latency abnormality of patients of above two groups were found for all the Wave forms. (Fig.2) Proportion of diabetic patients was higher having above normal levels of all the above Wave forms.

Table II: Association of duration of diabetes and BERA findings

\begin{tabular}{|c|c|c|c|c|c|c|c|c|c|}
\hline \multirow{2}{*}{$\begin{array}{l}\text { BERA } \\
\text { WAVE }\end{array}$} & & \multicolumn{2}{|c|}{ BELOW NORMAL } & \multicolumn{2}{|c|}{ NORMAL } & \multicolumn{2}{|c|}{ ABOVE NORMAL } & \multicolumn{2}{|c|}{ STATISTICAL } \\
\hline & & NO. & $\%$ & No. & $\%$ & NO. & $\%$ & $\mathbf{C}^{2}$ & 'P' \\
\hline \multirow{2}{*}{ Wave I } & $\leq 5 \mathrm{yr}$ & 10 & 17.2 & 26 & 44.8 & 22 & 37.9 & 2.727 & 0.256 \\
\hline & $>5 \mathrm{yr}$ & 43 & 28.3 & 60 & 39.5 & 49 & 32.2 & & \\
\hline \multirow{2}{*}{ Wave III } & $\leq 5 \mathrm{yr}$ & 19 & 32.8 & 16 & 27.6 & 23 & 39.7 & 0.873 & 0.646 \\
\hline & $>5 \mathrm{yr}$ & 40 & 26.3 & 47 & 30.9 & 65 & 42.8 & & \\
\hline \multirow{2}{*}{ Wave V } & $\leq 5 \mathrm{yr}$ & 10 & 17.2 & 20 & 34.5 & 28 & 48.3 & 7.354 & 0.025 \\
\hline & $>5 \mathrm{yr}$ & 22 & 14.5 & 28 & 18.4 & 102 & 67.1 & & \\
\hline \multirow{2}{*}{$\begin{array}{c}\text { Wave } \\
\text { I-III }\end{array}$} & $\leq 5 \mathrm{yr}$ & 21 & 36.2 & 5 & 86.2 & 32 & 55.2 & 0.322 & 0.851 \\
\hline & $>5 \mathrm{yr}$ & 59 & 38.8 & 10 & 6.6 & 83 & 54.6 & & \\
\hline \multirow{2}{*}{$\begin{array}{l}\text { Wave } \\
\text { III-V }\end{array}$} & $\leq 5 \mathrm{yr}$ & 39 & 67.2 & 1 & 1.7 & 18 & 31 & 0.711 & 0.701 \\
\hline & $>5 \mathrm{yr}$ & 93 & 61.2 & 4 & 2.6 & 55 & 36.2 & & \\
\hline $\begin{array}{c}\text { Wave } \\
\text { I-V }\end{array}$ & $\leq 5 \mathrm{yr}$ & 28 & 48.3 & 7 & 12.1 & 23 & 39.7 & 0.463 & 0.793 \\
\hline
\end{tabular}


HbAlc level did not show any significant association with degree of hearing loss (Pure-tone audiometry). HbAlc levels of diabetic patients attending the ENT OPD with all the above BERA and Pure tone audiometry parameters were found to be of Weak strength and non-significant in general. A near weak positive and statistically significant correlation of $\mathrm{HbA} 1 \mathrm{c}$ and Wave $\mathrm{V}$ was seen. (Table I) Association of duration of diabetes and BERA findings were not found to be significant for above wave forms except Wave V. (Table II)

\section{Discussion}

In view of the high risk of complications affecting almost every organ system, diabetes is considered more than a disease, rather a syndrome. Hearing loss is another complication frequently encountered by the diabetic patients. ${ }^{8-10}$ While hearing loss is not a newly discovered complications of diabetes, however, it is essential that it is identified at an early stage using more sensitive tools so that early rehabilitation of affected patients can be done and it could be prevented from subsequent progression. Moreover, an understanding of the clinicodemographic factors related with occurrence and progression of this hearing loss will provide an opportunity to prepare a preventive strategy by screening the diabetic population under higher risk. With this background, the present study was planned to evaluate sensorineural hearing loss in patient of type 2 diabetes mellitus by BERA. In some studies ${ }^{21,22}$ this ratio is even higher than 2 . With respect to sex-ratio (M:F), in present study it was 1.44 . Most of the other studies have also reported a higher proportion of males and sex-ratio above 1 . In some studies ${ }^{21,22}$ this ratio is even higher than 2. In present study, mean fasting blood sugar, random blood sugar and $\mathrm{HbA}$ lc levels of diabetic patients were $130.70 \pm 23.86 \mathrm{mg} / \mathrm{dl}, 163.77 \pm 49.12 \mathrm{mg} /$ $\mathrm{dl}$ and $6.42 \pm 1.33 \%$ respectively. Mozaffari et al. ${ }^{23}$ in their study reported mean blood sugar levels to be 175.3 and $157.7 \mathrm{mg} / \mathrm{dl}$ respectively for diabetic patients with and without sensorineural hearing loss. Sharma et al. ${ }^{24}$ in their study reported the mean fasting glucose levels of diabetic patients to be $117.6 \mathrm{mg} / \mathrm{dl}$ which is lower than present study. However, Joshi et al. ${ }^{25}$ reported fasting and PP blood sugar levels of diabetic patients as 155.65 and $222.86 \mathrm{mg} / \mathrm{dl}$ respectively both of which are higher than that in present study. In present study, all the diabetic cases as well as controls had sensorineural hearing loss as per PTA findings. On comparing the number of ears with moderately severe hearing loss it was found to be significantly higher in diabetics $(6.7 \%)$ as compared to non-diabetics ( $0 \%)$. Mozaffari et al. ${ }^{23}$ in their study reported that moderate or greater hearing loss was present in $13.9 \%$ of SNHL cases in diabetic group as compared to $6.3 \%$ of non-diabetic SNHL cases, thus showing proportion of those with more severe hearing loss to be higher in diabetic as compared to non-diabetic group. On evaluating the patients using BERA, we found delay in latency of all the three waves, i.e. I, III and $\mathrm{V}$ as well as for all the inter wave peaks (I-III, III-V and $\mathrm{I}-\mathrm{V}$ ) in both the ears for diabetic cases as compared to non-diabetic controls. Delayed latency for different waves and inter wave peaks have been reported to be characteristic of diabetes in almost all the previous studies. Batham et al. ${ }^{26}$ also reported BERA latencies to be significantly higher in diabetics as compared to controls for both the sides as observed in present study. Joshi et al. ${ }^{25}$ also found the latencies to be significantly longer in diabetic patients as compared to non-diabetic controls for all the waves except wave I and for all the interwave peaks except III-V. In present study, proportion of those having above normal wave latencies for different waves and interwave peaks was significantly higher in diabetic as compared to non-diabetic population for both the ears for all the waves and interwave peaks. These findings thus depict that latencies are delayed in diabetic patients more frequently than in a non-diabetic population.

In present study we did not find a significant association of level of glycaemic control (HbAlc) and duration of diabetes with presence and severity sensorineural of hearing loss. Correlation of $\mathrm{HbAlc}$ levels with BERA was also in general of weak order and for most of the wave and interwave latencies it was non-significant. A significant difference in BERA wave latencies was observed for level of glycemic control for wave $\mathrm{V}$ of both the ears only. Keeping in view the symptomatic profile of patients, relatively shorter duration of diabetes and a better glycaemic control profile of patients in present study, the prevalence of hearing loss in our patients cannot be totally attributable 
as diabetic complication. Nevertheless BERA studies showed characteristically delayed wave latencies in diabetic patients, thus showing that even partially diabetes has an effect on hearing ability which can be measured using sensitive measuring tools like BERA.

\section{Conclusions}

The findings of present study showed that among diabetic patient with sensorineural hearing loss (Cases) and non diabetic patients with sensorineural hearing loss (Controls) though there is not much difference with respect to prevalence of sensorineural hearing loss yet the severity of such hearing loss was significantly higher in diabetic patients (Cases)as compared to non-diabetic patients (Controls). Level of glycemic control showed a possible correlation with severity of hearing loss. Duration of diabetes also tended to have a significant association with longer latencies for wave $\mathrm{V}$ of BERA. The present study is the first study comparing the pattern of hearing loss in symptomatic diabetic patients and a non-diabetic symptomatic population in India. Further longitudinal studies in these two cohorts are recommended to assess the role of diabetes in determining the clinical course of hearing loss and its progression.

\section{References}

1. Kamba A, Daimon M, Murakami H, Otaka H, Matsuki K, Sato E, et al. Association between Higher Serum Cortisol Levels and Decreased Insulin Secretion in a General Population. PLoS One 2016; 11(11):e0166077

2. Wilcox G. Insulin and insulin resistance. Clin Biochem Rev. 2005; 26(2): 19-39

3. Toldo S, Boccellino M, Rinaldi B, Seropian M, Mezzaroma E, Severino A, et al. Altered oxido-reductive state in the diabetic heart: Loss of cardioprotection due to protein disulfide isomerase. Molecular Medicine 2011;17(9-10):1012-21

4. Joshi SR, Parikh RM. India - diabetes capital of the world: now heading towards hypertension. J Assoc Physicians India. 2007; $55: 323-4$

5. Wild S, Roglic G, Green A, Sicree R, King H. Global prevalence of diabetes-estimates for the year 2000 and projections for 2030. Diabetes Care 2004; 27(3): 1047-53

6. Mohan V, Deepa R. Obesity and abdominal obesity in Asian Indians. Indian J Med Res. 2006; 123(5):593-6
7. Kansagara D, Wolf F, Freeman M, Helfand M. Management of Inpatient Hyperglycemia: A Systematic Review [Internet]. Washington (DC): Department of Veterans Affairs (US); 2008

8. Akinpelu OV, Mujica-Mota M, Daniel SJ. Is type 2 diabetes mellitus associated with alterations in hearing? A systematic review and meta-analysis. Laryngoscope 2014; 124(3):767-76

9. Mitchell P, Gopinath B, McMahon CM, Rochtchina E, Wang JJ, Boyages SC, Leeder SR. Relationship of Type 2 diabetes to the prevalence, incidence and progression of age-related hearing loss. Diabet Med. 2009; 26(5):483-8

10. Horikawa C, Kodama S, Tanaka S, Fujihara K, Hirasawa R, Yachi Y, et al. Diabetes and risk of hearing impairment in adults: a meta-analysis. J Clin Endocrinol Metab. 2013; 98(1):51-8

11. Harner SG. Hearing in adult-onset diabetes mellitus. Otolaryngol Head Neck Surg. 1981; 89(2):322-7

12. Dalton DS, Cruickshanks KJ, Klein R, Klein BE, Wiley TL. Association of NIDDM and hearing loss. Diabetes Care 1998; 21(9): 1540-4

13. de España R, Biurrun O, Lorente J, Traserra J. Hearing and diabetes. ORL J Otorhinolaryngol Relat Spec. 1995; 57(6): 325-7

14. Ren T, Brown NJ, Zhang M, Nuttall AL, Miller JM. A reversible ischemia model in gerbil cochlea. Hear Res.1995; 92 (1-2):30-7

15. Nario $K$, Matsunaga $T$, Inui $H$, Murai $T$, Miyahara $H$. ABR findings, electrocochleograms and caloric tests in vertebrobasilar ischemic rats. Acta Otolaryngol Suppl. 1997; 528 (Suppl) :63-6

16. Perlman HB, Kimura R, Fernandez C. Experiments on temporary obstruction of the internal auditory artery. Laryngoscope 1959; 69 (6):591-613

17. Gupta A, Mandal S. Clinical significance of brainstem evoked response audiometry in patients with diabetes mellitus. Astrocyte 2018; 4: 217-20

18. Sharma A, Deshpande AA, Brid SV. A Comparative Study of Brainstem Evoked Response Audiometry in Diabetic and Nondiabetic Subjects. Sch. J. App. Med. Sci. 2016; 4(8):2950-6

19. American Diabetes Association. Diagnosis and classification of diabetes mellitus. Diabetes Care 2009; 32 (Suppl 1): S62-S67

20. American Diabetes Association. Diagnosis and classification of diabetes mellitus. Diabetes Care 2012;36 (Suppl 1): S67-S74

21. Gupta R, Aslam M, Hasan SA, Siddiqi SS. Type -2 diabetes mellitus and auditory brainstem responses-a hospital based study. Indian J Endocrinol Metab. 2010; 14(1): 9-11

22. Siddiqi SS, Gupta R, Aslam M, Hasan SA, Khan SA. Type2 diabetes mellitus and auditory brainstem response. Indian J Endocr Metab. 2013;17:1073-7

23. Mozaffari M, Tajik A, Ariaei N, Ali-Ehyaii F, Behnam H. Diabetes mellitus and sensorineural hearing loss among nonelderly people. East Mediterr Health J. 2010;16(9):947-52

24. Sharma A, Deshpande AA, Brid SV. A comparative study of brainstem evoked response audiometry in diabetic and 
nondiabetic subjects. Sch. J. App. Med. Sci. 2016; 4(8C):2950-

25. Joshi KD, Galagali JR, Kanzhuly MK, Singh ID. A comparative study on effects of diabetes on auditory functions as measured by BERA and DPOAE. Int J Otorhinolaryngol Head Neck
Surg. 2017; 3(2): 347-53

26. Batham C, Choudhary AK, Yousuf PS. Evaluation of auditory evoked response among type-II diabetic individuals in central India. Natl J Physiol Pharm Pharmacol. 2017;7(10):1061-9. 